\title{
Behavioural patterns of protective and risk factors for non-communicable diseases in Brazil
}

\author{
Eurídice Martínez Steele ${ }^{1, *}$, Rafael Moreira Claro ${ }^{1}$ and Carlos Augusto Monteiro ${ }^{1,2}$ \\ ${ }^{1}$ Center for Epidemiological Studies in Health and Nutrition, University of São Paulo (NUPENS/USP), \\ Av. Dr Arnaldo 715, São Paulo, SP, Brazil, CEP 01246-904: '² Department of Nutrition, School of Public Health, \\ University of São Paulo (FSP/USP), São Paulo, SP, Brazil
}

Submitted 28 May 2012: Final revision received 14 September 2012: Accepted 12 November 2012: First published online 11 January 2013

\begin{abstract}
Objective: To identify behavioural patterns of protective and risk factors for non-communicable diseases (NCD) and to explore the association between these patterns and sociodemographic characteristics.

Design: Principal component analysis was used to identify behavioural patterns from a list of twelve protective and risk factors for NCD. Linear regression was used to explore the association between the patterns and sociodemographic characteristics.

Setting: Participants from the Brazilian Surveillance System of Risk and Protective Factors for NCD through Telephone Interviews (VIGITEL) from the years 2009 and 2010 were included.

Subjects: A sample of 108706 adults was included in the analysis.

Results: Two behavioural patterns were identified in the analysis, a 'prudent pattern' and a 'risky pattern'. The first involved mostly protective behaviours, while the second one involved essentially the risky ones. Both the less prudent and the more risky behaviour patterns were concentrated in younger men, with lower education, from the more developed region.

Conclusions: Public policies to decrease NCD should be aware of the possible tendency towards behavioural patterns in order to be more effective.
\end{abstract}

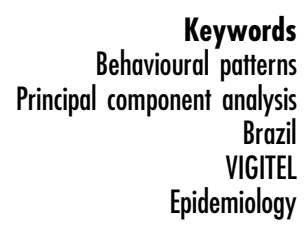

Non-communicable diseases (NCD) play an important role in the morbidity and mortality of human populations both worldwide and in Brazil. According to the WHO, NCD were responsible for $58.5 \%$ of all deaths worldwide and for $45.9 \%$ of the global burden of disease in $2001^{(1)}$. In Brazil in 2004, NCD were the primary cause of $62.8 \%$ of all deaths with known cause ${ }^{(2)}$. Furthermore, the proportion of deaths due to NCD in the Brazilian state capitals has more than tripled between the 1930s and the $1990 s^{(3)}$. It has been estimated that in Brazil, NCD were responsible for $59 \%$ of the total years of life lost due to premature death and for $66 \cdot 3 \%$ of disability-adjusted life years in $1998^{(3)}$.

According to the WHO, a small number of modifiable risk factors are responsible for the majority of deaths and for an important part of the global burden of disease due to NCD. These factors include smoking, alcohol abuse, obesity, excessive saturated fat intake, insufficient fruit and vegetable intake and physical inactivity ${ }^{(1)}$

In order to monitor the prevalence of the main NCD risk factors, in 2006 the Brazilian Ministry of Health started an ongoing Surveillance System of Risk and Protective Factors for Non Communicable Diseases through Telephone Interviews (Vigilância de Fatores de Risco e Proteção para
Doenças Crônicas por Inquérito Telefônico, VIGITEL) ${ }^{(4)}$. To date, analyses based on the data from VIGITEL have focused mainly on exploring the frequency and distribution of risk and protective factors for NCD individually $^{(5,6)}$. Using multivariate techniques to understand how the different risk and protective factors are grouped in the population as behavioural patterns is an important step towards measuring the combined effect of different variables on the prevention of NCD.

Some researchers have found that the risk of developing an NCD increases with the number of unhealthy behaviours such as smoking, excessive alcohol consumption, unhealthy dietary habits and sedentary behaviour ${ }^{(7-10)}$. The fact that some unhealthy behaviours may interact, producing an even greater risk than if the individual risks are added together ${ }^{(11,12)}$, may be an important issue to consider in health promotion ${ }^{\text {(7) }}$.

Furthermore, as Hu pointed out in $2002^{(13)}$, with regard to nutritional epidemiology and the conceptual and methodological limitations of studying a single food or nutrient as a risk factor, we may highlight the following drawbacks to studying a single behavioural risk factor in contrast to studying behavioural patterns. First of all, people are not exposed to single risk factors but to a 
combination of them which are frequently interactive or synergistic. Second, the high level of intercorrelation between some single risk factors makes it difficult to study their effects separately. Third, the effect of a single risk factor may be too small to detect; this may not happen with the cumulative effect of all of the risk factors included in a behavioural pattern. Fourth, statistically significant associations may be due to chance in analyses which include a large number of risk factors. Last of all, single risk factor analysis may be confounded by behavioural patterns ${ }^{(13)}$.

Principal component analysis (PCA) is a mathematical model that allows the reduction of several variables into a smaller number of components (patterns) which are uncorrelated linear combinations of the initial variables and which maximize the explained variance. The PCA can offer some benefits such as overcoming collinearity or measuring the combined effect of different behaviours ${ }^{(13)}$.

Most published studies have focused on using PCA to define dietary patterns rather than behavioural patterns which include not only diet but other risk and protective indicators such as alcohol abuse, smoking or physical activity. Many of these studies have identified a 'prudent pattern' defined by higher fruit, vegetable, whole grains, fish and poultry intakes and a 'Western pattern' richer in fat, meat and refined grains ${ }^{(14)}$.

The present study aimed to identify behavioural patterns of protective and risk factors for NCD and to explore the association between these patterns and sociodemographic characteristics in the population living in the twenty-six Brazilian state capitals and the Federal District.

\section{Methods}

\section{Source population and study design}

Data from VIGITEL from the years 2009 and 2010 were used in the present study. VIGITEL is a surveillance system based on telephone interviews which was developed and implemented in the capital of the state of São Paulo in $2003^{(15)}$ and expanded to the other state capitals and the Federal District of Brazil in $2006^{(16)}$. Every year the system interviews a probabilistic sample of $\sim 54000$ adults (aged 18 years or older) living in households with a landline telephone in the twenty-six Brazilian state capitals and the Federal District.

In each city, sampling is performed in two steps: random selection of households with landline telephones in the first step and random selection of prospective interviewees in the second. A minimum of 2000 interviews are conducted in each city to ensure a maximum error of $2 \%$ and a $95 \%$ confidence interval in the estimation of any of the surveyed data. Due to the similarity between the proportions of men and women in the survey sample, maximum errors of $3 \%$ are expected for certain data frequency estimates reported by sex. Further details regarding the sampling procedure have been published previously ${ }^{(15,16)}$.
Interviews collect information about sociodemographic characteristics, food consumption, physical activity, smoking, alcohol abuse, UV protection, self-reported weight and height, and self-reported medical diagnosis of several health conditions.

\section{Variable description}

In our study, the following indicators were included as protective factors: (i) bean consumption on $\geq 5 \mathrm{~d} /$ week ('Regular bean consumption'); (ii) vegetable consumption on $\geq 5 \mathrm{~d}$ /week ('Regular vegetable consumption'); (iii) consumption of fresh fruit juice daily ('Daily freshfruit juice consumption'); (iv) fruit consumption on $\geq 5 \mathrm{~d}$ /week ('Regular fruit consumption'); (v) consumption of reduced-fat milk ('Fat-reduced milk consumption'); (vi) practice of low or moderate physical activity for $\geq 30 \mathrm{~min} / \mathrm{d}$ on $\geq 5 \mathrm{~d} /$ week or practice of intensive physical activity for $20 \mathrm{~min} / \mathrm{d}$ on $\geq 3 \mathrm{~d}$ /week ('Sufficient leisuretime physical activity'); and (vii) daily sun exposure of $<30 \mathrm{~min}$, or otherwise use of sunscreen, hat/sunshade and appropriate clothing ('Efficient protection against UV radiation').

Regarding the risk factors, the following indicators were considered: (i) habit of consuming visible fat in fat-rich red meat or poultry skin ('Fat-rich meat consumption'); (ii) consumption of soft drinks on $\geq 5 \mathrm{~d}$ /week ('Regular soft drink consumption'); (iii) consumption of $>4$ (women) or $>5$ (men) alcoholic beverages in a single occasion in the past $30 \mathrm{~d}$, where one alcoholic beverage is equivalent to one measure of a distilled beverage, one can of beer or one glass of wine ('Excessive alcoholic beverage consumption'); (iv) watching television for $>3 \mathrm{~h} / \mathrm{d}$ on $\geq 5 \mathrm{~d} /$ week ('Watching television in excess'); and (v) smoking, independently of the frequency and intensity of the smoking habit ('Smoking').

Both risk and protective factors were analysed as dichotomous variables ('yes' or 'no').

The following sociodemographic covariables were taken into account in the study: (i) gender; (ii) region (more developed $=$ Centre-West, Southeast and South; less developed $=$ Northeast and North); (iii) age in years (18-24; 25-34; 35-44; 45-54; 55-64; $\geq 65$ ); and (iv) years of schooling $(0-8 ; 9-11 ; \geq 12)$. Missing information regarding years of schooling were imputed according to the mean valid values for the same sex and age.

\section{Statistical analysis}

The sociodemographic distribution and the frequency of protective and risk factor indicators were estimated in the sample.

Using PCA (through the correlation matrix) we identified the behavioural patterns in the sample. Protective and risk disease indicators from the questionnaire were entered in the PCA and the number of components retained was based on the Kaiser criterion (eigenvalue $>1 \cdot 0$ ) and the interpretability of the components. The components were 
rotated using the varimax procedure in order to facilitate the interpretability of the results.

Linear regression was used to study the association between the score of each of the two factors and the chosen sociodemographic characteristics in multivariateadjusted models. We adjusted for the following potential confounders in the regression models: gender, region, age and years of schooling.

VIGITEL data include weighting factors designed in order to avoid design bias and allow the data to represent the entire population of each study site. Weighting factors were developed in three stages: the first was designed to reflect the ratio between the number of adults living in each household and the number of telephone landlines; the second took into account the ratio between the percentage of people in a given census category (by sex, age and education level) from the year 2000 and the percentage of the same category in VIGITEL; and the third factor considered the ratio between adults living in each city and adults studied through VIGITEL ${ }^{(17)}$.

No re-weighting was incorporated in the estimation of the correlation matrix in the PCA. Re-weighting was considered in all other analyses.

The Stata statistical software package version 11 was used to perform the analyses. All mentioned analyses were performed in the complete sample and separately for men and women. All $P$ values were two-sided.

VIGITEL was approved by the National Human Research Ethics Committee of the Brazilian Ministry of Health.

\section{Results}

The sociodemographic characteristics for the total sample ( $n$ 108706) and among men and women separately are shown in Table 1 (weighted values). Fifty per cent of the data came from the 2009 sample and $50 \%$ from the 2010 sample. Men represented $46 \cdot 1 \%$ of the sample and $63.4 \%$ of the sample were from the more developed region. The percentage of people in each age group ranged between $8 \cdot 6 \%$ (in the $\geq 65$ years age group) and $25 \cdot 3 \%$ (in the $25-34$ years age group). The group with $0-8$ years of schooling represented $53.3 \%$ of the sample, $30 \cdot 0 \%$ had $9-11$ years of schooling and $16 \cdot 6 \%$ had $\geq 12$ years of schooling.

The frequencies of the protective and risk factor indicators included in the PCA are displayed in Table 2 (weighted values). The protective factors are listed first and the risk factors follow. Sixty-six per cent of the sample ate beans regularly, $44.3 \%$ ate vegetables regularly, $71 \cdot 2 \%$ consumed fresh fruit juice daily, $57 \cdot 1 \%$ consumed fruit regularly, $16.9 \%$ consumed fat-reduced milk, $14 \cdot 8 \%$ practised sufficient physical activity during leisure time and $46 \cdot 2 \%$ of the sample practised efficient protection against UV radiation. With regard to the risk factors, $33.6 \%$ consumed fat-rich meat, $24 \cdot 9 \%$ consumed soft drinks regularly, $18.5 \%$ consumed alcohol in excess, $27 \cdot 0 \%$ watched television in excess and $15.3 \%$ were current smokers.

Through PCA, four of the twelve components had an eigenvalue $>1.0$ and explained $42 \%$ of the variance in men and $43 \%$ in women. Based on the interpretability of each component, two components were retained in men and women. After rotation, these two components explained $\sim 25 \%$ of the variance in men and $26 \%$ of the variance in women. The rotated factor loadings on each of the two components, for the total sample and among men and women separately, are displayed in Table 3 (factor loadings above 0.25 and below -0.25 have been indicated in bold font).

The first component, hereafter termed the 'prudent pattern', was very similar for men and women and was

Table 1 Sociodemographic characteristics of the sample by gender. Brazilian Surveillance System of Risk and Protective Factors for NCD through Telephone Interviews (VIGITEL), 2009-2010

\begin{tabular}{|c|c|c|c|c|c|c|}
\hline \multirow[b]{2}{*}{ Characteristic } & \multicolumn{2}{|c|}{ Total $(n$ 108706) } & \multicolumn{2}{|c|}{ Male ( $n$ 42111) } & \multicolumn{2}{|c|}{ Female ( $n$ 66 595) } \\
\hline & Weighted \% & $95 \% \mathrm{Cl}$ & Weighted \% & $95 \% \mathrm{Cl}$ & Weighted \% & $95 \% \mathrm{Cl}$ \\
\hline \multicolumn{7}{|l|}{ Regiont } \\
\hline More developed & $63 \cdot 4$ & $62 \cdot 7,64 \cdot 2$ & $63 \cdot 7$ & $62 \cdot 5,64 \cdot 9$ & $63 \cdot 3$ & $62 \cdot 4,64 \cdot 1$ \\
\hline Less developed & $36 \cdot 6$ & $35 \cdot 8,37 \cdot 3$ & $36 \cdot 3$ & $35 \cdot 1,37 \cdot 5$ & $36 \cdot 7$ & $35 \cdot 9,37 \cdot 6$ \\
\hline \multicolumn{7}{|l|}{ Age (years) } \\
\hline $18-24$ & $21 \cdot 5$ & $20 \cdot 5,22 \cdot 5$ & $22 \cdot 4$ & $20 \cdot 6,24 \cdot 2$ & $20 \cdot 7$ & $19 \cdot 6,21 \cdot 8$ \\
\hline $25-34$ & $25 \cdot 3$ & $24 \cdot 6,26 \cdot 1$ & $26 \cdot 1$ & $24 \cdot 8,27 \cdot 3$ & $24 \cdot 7$ & $23 \cdot 8,25 \cdot 6$ \\
\hline $35-44$ & $21 \cdot 3$ & $20 \cdot 7,21 \cdot 9$ & $21 \cdot 5$ & $20 \cdot 6,22 \cdot 5$ & $21 \cdot 1$ & $20 \cdot 4,21 \cdot 8$ \\
\hline $45-54$ & $14 \cdot 6$ & $14 \cdot 2,15 \cdot 1$ & $14 \cdot 5$ & $13 \cdot 8,15 \cdot 2$ & $14 \cdot 7$ & $14 \cdot 2,15 \cdot 3$ \\
\hline $55-64$ & $8 \cdot 7$ & $8 \cdot 3,8 \cdot 9$ & $8 \cdot 3$ & $7 \cdot 8,8 \cdot 8$ & 8.9 & $8 \cdot 6,9 \cdot 4$ \\
\hline$\geq 65$ & $8 \cdot 6$ & $8 \cdot 3,8.9$ & $7 \cdot 2$ & $6 \cdot 8,7 \cdot 7$ & $9 \cdot 8$ & $9 \cdot 4,10 \cdot 2$ \\
\hline \multicolumn{7}{|l|}{ Years of schooling } \\
\hline $0-8$ & $53 \cdot 3$ & $52 \cdot 5,54 \cdot 2$ & $53 \cdot 7$ & $52 \cdot 3,55 \cdot 1$ & $53 \cdot 0$ & $52 \cdot 1,54 \cdot 0$ \\
\hline $9-11$ & $30 \cdot 0$ & $29 \cdot 4,30 \cdot 7$ & $29 \cdot 1$ & $28 \cdot 1,30 \cdot 2$ & $30 \cdot 8$ & $30 \cdot 0,31 \cdot 6$ \\
\hline$\geq 12$ & $16 \cdot 6$ & $16 \cdot 2,17 \cdot 0$ & $17 \cdot 2$ & $16 \cdot 4,17 \cdot 9$ & $16 \cdot 1$ & $15 \cdot 6,16 \cdot 6$ \\
\hline Total & \multicolumn{2}{|c|}{$100 \cdot 0$} & $46 \cdot 1$ & $45 \cdot 2,46 \cdot 9$ & $53 \cdot 9$ & $53 \cdot 0,54 \cdot 8$ \\
\hline
\end{tabular}

tMore developed region $=$ Centre-West, Southeast and South; less developed region $=$ Northeast and North . 
Table 2 Frequency (\%) of behavioural protective and risk factor indicators in the sample by gender. Brazilian Surveillance System of Risk and Protective Factors for NCD through Telephone Interviews (VIGITEL), 2009-2010

\begin{tabular}{|c|c|c|c|c|c|c|}
\hline \multirow[b]{2}{*}{ Indicatort } & \multicolumn{2}{|c|}{ Total $(n 108706)$} & \multicolumn{2}{|c|}{ Male ( $n$ 42111) } & \multicolumn{2}{|c|}{ Female ( $n$ 66595) } \\
\hline & Weighted \% & $95 \% \mathrm{Cl}$ & Weighted \% & $95 \% \mathrm{Cl}$ & Weighted \% & $95 \% \mathrm{Cl}$ \\
\hline Regular bean consumption & $66 \cdot 2$ & $65 \cdot 5,67 \cdot 0$ & $72 \cdot 3$ & $71 \cdot 1,73 \cdot 5$ & $61 \cdot 1$ & $60 \cdot 1,62 \cdot 0$ \\
\hline Regular vegetable consumption & $44 \cdot 3$ & $43 \cdot 4,45 \cdot 1$ & $38 \cdot 8$ & $37 \cdot 5,40 \cdot 1$ & $48 \cdot 9$ & $47 \cdot 9,49 \cdot 9$ \\
\hline Daily fresh-fruit juice consumption & $71 \cdot 2$ & $70 \cdot 4,71 \cdot 9$ & $74 \cdot 8$ & $73 \cdot 6,76 \cdot 1$ & $68 \cdot 0$ & $67 \cdot 1,69 \cdot 0$ \\
\hline Regular fruit consumption & $57 \cdot 1$ & $56 \cdot 2,58 \cdot 0$ & $51 \cdot 6$ & $50 \cdot 1,53 \cdot 1$ & $61 \cdot 8$ & $60 \cdot 8,62 \cdot 8$ \\
\hline Fat-reduced milk consumption & $16 \cdot 9$ & $16 \cdot 4,17 \cdot 4$ & $14 \cdot 5$ & $13 \cdot 7,15 \cdot 2$ & $18 \cdot 9$ & $18 \cdot 3,19 \cdot 7$ \\
\hline Sufficient leisure-time physical activity & $14 \cdot 8$ & $14 \cdot 3,15 \cdot 4$ & $18 \cdot 7$ & $17 \cdot 7,19 \cdot 7$ & $11 \cdot 5$ & $10 \cdot 9,12 \cdot 1$ \\
\hline Efficient protection against UV radiation & $46 \cdot 2$ & $45 \cdot 3,47 \cdot 1$ & $36 \cdot 5$ & $35 \cdot 2,37 \cdot 9$ & $54 \cdot 5$ & $53 \cdot 4,55 \cdot 5$ \\
\hline Fat-rich meat consumption & $33 \cdot 6$ & $32 \cdot 8,34 \cdot 4$ & $44 \cdot 4$ & $42 \cdot 9,45 \cdot 8$ & $24 \cdot 4$ & $23 \cdot 4,25 \cdot 3$ \\
\hline Regular soft drink consumption & $24 \cdot 9$ & $24 \cdot 0,25 \cdot 9$ & $28 \cdot 2$ & $26 \cdot 6,29 \cdot 9$ & $22 \cdot 1$ & $21 \cdot 2,23 \cdot 1$ \\
\hline Excessive alcoholic beverage consumption & $18 \cdot 5$ & $17 \cdot 8,19 \cdot 1$ & $27 \cdot 8$ & $26 \cdot 6,29 \cdot 0$ & $10 \cdot 5$ & $9 \cdot 9,11 \cdot 1$ \\
\hline Watching television in excess & $27 \cdot 0$ & $26 \cdot 1,27 \cdot 9$ & $27 \cdot 6$ & $25 \cdot 9,29 \cdot 3$ & $26 \cdot 5$ & $25 \cdot 6,27 \cdot 4$ \\
\hline Smoking & $15 \cdot 3$ & $14 \cdot 6,15 \cdot 9$ & $18 \cdot 5$ & $17 \cdot 3,19 \cdot 6$ & $12 \cdot 6$ & $11 \cdot 8,13 \cdot 4$ \\
\hline
\end{tabular}

tFor details on indicators, see Methods section.

characterized by regular vegetable consumption, daily fresh-fruit juice consumption, regular fruit consumption, fat-reduced milk consumption, sufficient physical activity practice during leisure time, efficient protection against UV radiation and reduced regular soft drink consumption (variables with factor loadings above 0.25 and below $-0 \cdot 25)$.

The second component, hereafter called the 'risky pattern', was defined by fat-rich meat consumption, excessive alcoholic beverage intake and current smoking habit in the total sample and both men and women. In men, watching television in excess also showed a factor loading above 0.25 in this component. In women, it was regular soft drink consumption which presented a factor loading above $0 \cdot 25$.

As illustrated in Table 4 (multivariate-adjusted weighted models), individuals with higher scores on the first component were more likely to be female, from the less developed region, older, and with more years of schooling. Regarding the second component, individuals with higher scores were more likely to be male, from the more developed region, younger, and with less years of schooling. This held true as well when men and female were analysed separately.

\section{Discussion}

The detailed record of information about risk and protective behaviours for non-communicable diseases made by VIGITEL, in more than 100000 interviews, allowed the identification of clear patterns of behaviour in the Brazilian population. Two behavioural patterns have been identified in the present analysis. The first one, the prudent pattern, was defined by regular vegetable consumption, daily fresh-fruit juice consumption, regular fruit consumption, fat-reduced milk consumption, sufficient physical activity practice during leisure time, efficient protection against UV radiation and reduced regular soft drink consumption.
The prudent pattern showed a positive association with being female, from the less developed region, with age and with years of schooling.

The second one, the risky pattern, was characterized by fat-rich meat consumption, excessive alcoholic beverage intake and current smoking habit. While in men watching television in excess also defined this pattern, in women it was regular soft drink consumption that did. This pattern was negatively associated with being female, from the less developed region, with age and with years of schooling.

The main limitation of the present study is that the survey sample included only the population from the twenty-seven studied cities that had a landline telephone, which coverage varied from city to city between $34 \%$ and $82 \%{ }^{(18)}$. This implies that the results from the study can be generalized only to the urban Brazilian population with a landline telephone. However, the selection bias generated by the over-representation of women, older in age and with more years of schooling in the VIGITEL sample was minimized through the use of post-stratification weights, as is done in similar studies such as the Behavioral Risk Factor Surveillance System (BRFSS) in the USA ${ }^{(16,19)}$.

Given the fact that in Brazil the census is performed every 10 years, VIGITEL was forced to weight the distribution of gender, age and years of schooling according to the Brazilian national census for the year 2000. This could also be considered a limitation as the post-stratification weights may not correspond exactly to the targeted population in the 2009 and 2010 samples.

Also, it is important to consider several limitations inherent to the use of PCA, including the following arbitrary choices: the number of components to extract, the method of rotation and the naming of the components ${ }^{(20)}$.

We have no knowledge of other studies in which food intake and non-dietary health behavioural variables have been jointly used to establish patterns through the use of PCA. As not only diet but other indicators such as 


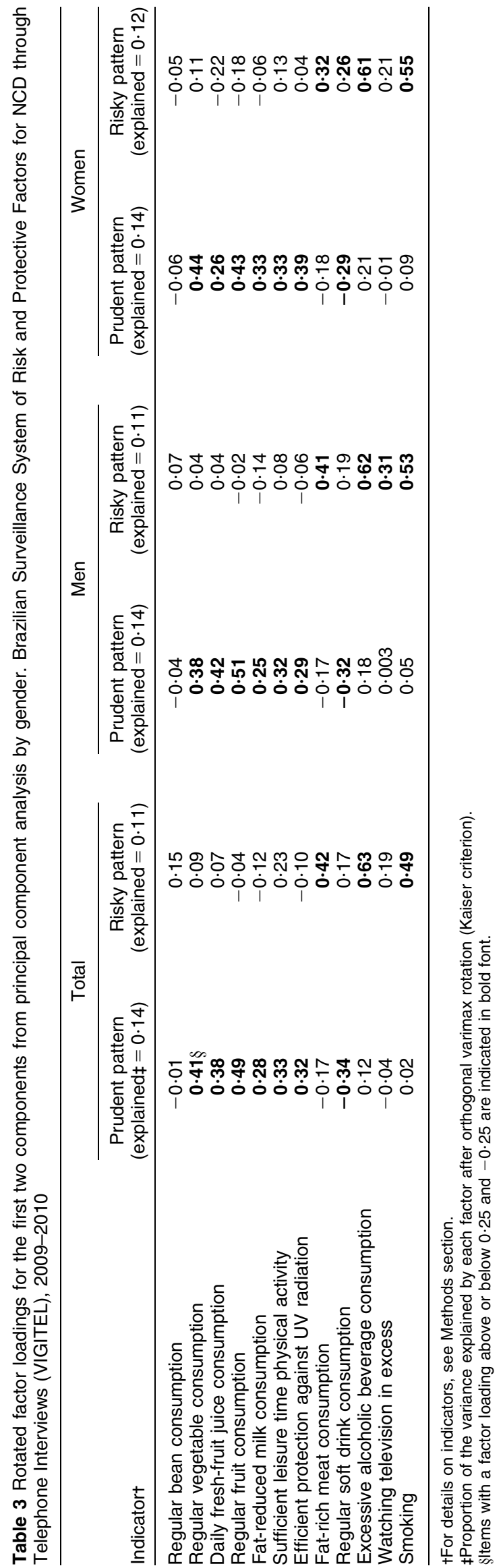

smoking, physical activity and alcohol intake are known to be risk factors for NCD, we consider that it is important to identify behavioural patterns that include both dietary and non-dietary variables.

The present study shows that protective and risk indicators group together in behavioural patterns (prudent and risky patterns) in different subgroups of the Brazilian population. Our findings seem consistent with what has been published in studies that have performed PCA using exclusively dietary indicators. Most of these have identified a prudent pattern defined by higher intakes of fruit, vegetables, whole grains, fish and poultry and a Western pattern richer in fat, meat and refined grains $^{(13,14)}$. In accordance with our results, other studies have found that the more healthy dietary patterns have a positive association with age and education ${ }^{(14)}$.

Some studies have shown that health behaviours, when analysed independently, are associated with sociodemographic characteristics such as gender, age and educational level $^{(21,22)}$. For example, Finnish women behave more healthily than men regarding all risk factors with the exception of the fact that they perform less physical activity ${ }^{(7)}$. Yet when analysed as patterns (i.e. through the use of a number of risk factors), most people have shown mixed combinations of both healthy and unhealthy behaviours and completely healthy or unhealthy patterns were infrequent ${ }^{(23,24)}$. Even so, the number of people with multiple unhealthy behaviours has been shown to be more frequent than expected if the behaviours were not related to each other ${ }^{(25,26)}$. This is in agreement with our findings by which healthy and unhealthy behaviours group together in the prudent and risky patterns, respectively, both patterns being associated with gender, age, region and years of schooling.

Two health promotion strategies can be used in the prevention of NCD: a population-based one, which may have significant net effects, and a high risk one, which may have higher costs per person but prove to be more cost-efficient ${ }^{(7,27)}$. The fact that previous findings have shown there is a positive association between the number of risk factors and development of $\mathrm{NCD}^{(7-10)}$ can be an indication that certain subgroups could be targeted when designing campaigns to incentivize healthy behaviours and dissuade risky ones. If a high risk approach were to be used, public health measures to decrease NCD should aim on reaching younger men, with lower education, from the more developed region in order to improve their efficiency as it is in this subgroup in which both the prudent and the risky pattern behaviours are concentrated.

We consider that future studies should concentrate on both the identification of behavioural patterns through PCA and the exploration of the association between these and NCD outcomes. The fact that studies exploring the association between dietary patterns and NCD are not consistent further enhances this need. While some studies have found a negative association between higher 
Table 4 Multivariate-adjusted weighted means for the two factor scores, adjusted for gender, region, age and schooling, by gender. Brazilian Surveillance System of Risk and Protective Factors for NCD through Telephone Interviews (VIGITEL), 2009-2010

\begin{tabular}{|c|c|c|c|c|c|c|}
\hline & \multicolumn{2}{|c|}{ Total (n 108706) } & \multicolumn{2}{|c|}{ Men $(n 42111)$} & \multicolumn{2}{|c|}{ Women (n 66 595) } \\
\hline & $\begin{array}{l}\text { Prudent pattern } \\
\qquad\left(R^{2}=0.09\right)\end{array}$ & $\begin{array}{l}\text { Risky pattern } \\
\left(R^{2}=0 \cdot 13\right)\end{array}$ & $\begin{array}{l}\text { Prudent pattern } \\
\qquad\left(R^{2}=0.09\right)\end{array}$ & $\begin{array}{l}\text { Risky pattern } \\
\left(R^{2}=0.06\right)\end{array}$ & $\begin{array}{l}\text { Prudent pattern } \\
\qquad\left(R^{2}=0.09\right)\end{array}$ & $\begin{array}{c}\text { Risky pattern } \\
\left(R^{2}=0.04\right)\end{array}$ \\
\hline & Coef. $t^{\prime}$ & Coef. & Coef. & Coef. & Coef. & Coef. \\
\hline \multicolumn{7}{|l|}{ Gender } \\
\hline Male & 0 & 0 & & & & \\
\hline Female & $0 \cdot 26^{\star \star \star}$ & $-0 \cdot 70^{\star \star \star}$ & & & & \\
\hline \multicolumn{7}{|l|}{ Region } \\
\hline More developed & 0 & 0 & 0 & 0 & 0 & 0 \\
\hline Less developed & $0 \cdot 26^{\star \star \star}$ & $-0 \cdot 15^{\star \star \star}$ & $0 \cdot 37^{\star \star \star}$ & $-0.09^{\star \star}$ & $0 \cdot 13^{\star \star \star}$ & $-0 \cdot 34^{\star \star \star}$ \\
\hline \multicolumn{7}{|l|}{ Age (years) } \\
\hline $18-24$ & 0 & 0 & 0 & 0 & 0 & 0 \\
\hline $25-34$ & 0.07 & -0.004 & 0.01 & 0.08 & $0 \cdot 15^{\star \star}$ & -0.05 \\
\hline $35-44$ & $0 \cdot 22^{\star \star \star}$ & $-0 \cdot 21^{\star * \star}$ & 0.08 & $-0 \cdot 19^{\star \star}$ & $0 \cdot 35^{\star \star \star}$ & $-0 \cdot 18^{\star \star \star}$ \\
\hline $45-54$ & $0 \cdot 38^{\star \star \star}$ & $-0 \cdot 29^{\star \star \star}$ & $0 \cdot 18^{\star \star}$ & $-0 \cdot 29^{\star \star \star}$ & $0 \cdot 55^{\star \star \star}$ & $-0 \cdot 21^{\star \star \star}$ \\
\hline $55-64$ & $0 \cdot 60^{\star \star \star}$ & $-0.54^{\star \star \star}$ & $0.42^{\star \star \star}$ & $-0.52^{\star \star \star}$ & $0 \cdot 72^{\star \star \star}$ & $-0 \cdot 49^{\star \star \star}$ \\
\hline$\geq 65$ & $0 \cdot 78^{\star \star \star}$ & $-0 \cdot 85^{\star \star \star}$ & $0 \cdot 55^{\star \star \star}$ & $-0 \cdot 89^{\star \star \star}$ & $0 \cdot 89^{\star \star \star}$ & $-0 \cdot 78^{\star \star \star}$ \\
\hline \multicolumn{7}{|l|}{ Years of schooling } \\
\hline $0-8$ & 0 & 0 & 0 & 0 & 0 & 0 \\
\hline $9-11$ & $0 \cdot 36^{\star \star \star}$ & $-0 \cdot 16^{\star \star \star}$ & $0 \cdot 35^{\star \star \star}$ & $-0 \cdot 20^{\star \star \star}$ & $0 \cdot 35^{\star \star \star}$ & $-0 \cdot 17^{\star \star \star}$ \\
\hline$\geq 12$ & $0 \cdot 89^{\star \star \star}$ & $-0 \cdot 29^{\star \star \star}$ & $0 \cdot 88^{\star \star \star}$ & $-0 \cdot 36^{\star \star \star}$ & $0.93^{\star \star \star}$ & $-0 \cdot 27^{\star \star \star}$ \\
\hline Constant & $-1 \cdot 08^{\star \star \star}$ & $0.94^{\star \star \star}$ & $-0 \cdot 79^{\star \star \star}$ & $0 \cdot 48^{\star \star \star}$ & $-0.99^{\star \star \star}$ & $0.59^{\star \star \star}$ \\
\hline
\end{tabular}

tRegression coefficient: ${ }^{\star} P \leq 0 \cdot 05 ;{ }^{* \star} P \leq 0.01 ;{ }^{* * *} P \leq 0.001$.

¥More developed region $=$ Centre-West, Southeast and South; less developed region $=$ Northeast and North.

prudent diet scores and NCD outcomes ${ }^{(28-33)}$ and a positive association between higher Western diet scores and NCD outcomes ${ }^{(29,30,32,33)}$, others have failed to show any association ${ }^{(34)}$.

\section{Acknowledgements}

Sources of funding: The present research was funded by the National Council for Scientific and Technological Development (CNPq - Process No. 486072/2011-8). A postdoctoral fellowship was received from the São Paulo State Research Foundation (no. 2010/08421-7). Conflicts of interest: The authors declare that they have no conflicts of interest. Authors' contributions: R.M.C. and C.A.M. conceived the project. All authors (E.M.S., R.M.C., C.A.M.) contributed to the conception, design, analysis, interpretation and discussion of the data, and all authors drafted and revised the initial version of the manuscript and contributed to and approved the final version.

\section{References}

1. World Health Organization (2002) World Health Report 2002. Reducing Risks, Promoting Healthy Life. Geneva: WHO.

2. Ministério da Saúde, Secretaria de Vigilância em Saúde, Departamento de Análise de Situação em Saúde (2006) Saúde Brasil 2006: uma análise da situação de saúde no Brasil. Brasília: Ministério da Saúde.

3. Malta DC, Cezário AC, Moura L et al. (2006) A construção da vigilância e prevenção das doenças crônicas não trasmissíveis no contexto do sistema único de saúde. Epidemiol Serv Saude 15, 47-65.
4. Ministério da Saúde (2011) Vigitel Brasil 2010: vigilância de fatores de risco e proteção para doenças crônicas por inquérito telefônico. Brasília: Ministério da Saúde.

5. Jaime PC, Figueiredo ICR, Moura EC et al. (2009) Fatores associados ao consumo de frutas e hortaliças no Brasil, 2006. Rev Saude Publica 43, Suppl. 2, 57-64.

6. Gigante DP, Moura EC \& Sardinha LMV (2009) Prevalência de excesso de peso e obesidade e fatores associados, Brasil, 2006. Rev Saude Publica 43, Suppl. 2, 83-89.

7. Laaksonen M, Prattaila R \& Lahelma E (2003) Sociodemographic determinants of multiple unhealthy behaviours. Scand J Public Health 31, 37-43.

8. Pickett W, Garner M, Biyce WF et al. (2002) Gradients in risk for youth injury associated with multiple-risk behaviours: a study of 11,329 Canadian adolescents. Soc Sci Med 55, 1055-1068.

9. Berkman L \& Breslow L (1983) Health and Ways of Living. The Alameda County Study. New York: Oxford University Press.

10. Segovia J, Bartlett RF \& Edwards AC (1991) Health status and health practices: Alameda and beyond. Int J Epidemiol 20, 259-263.

11. Luoto R, Prätälä R \& Lutela A (1998) Impact of unhealthy behaviors on cardiovascular mortality in Finland, 1978-1993. Prev Med 27, 93-100.

12. Meng L, Maskarinec G, Lee J et al. (1999) Lifestyle factors and chronic diseases: application of a composite risk index. Prev Med 29, 296-304.

13. Hu FB (2002) Dietary pattern analysis: a new direction in nutritional epidemiology. Curr Opin Lipidol 13, 3-9.

14. Kant AK (2004) Dietary patterns and health outcomes. J Am Diet Assoc 104, 615-635.

15. Monteiro CA, de Moura EC, Jaime PC et al. (2005) Surveillance of risk factors for chronic diseases through telephone interviews. Rev Saude Publica 39, 47-57.

16. Moura EC, Malta DC, Morais Neto OL et al. (2009) Prevalence and social distribution of risk factors for chronic noncommunicable diseases in Brazil. Rev Panam Salud Publica 26, 17-22.

17. Moura EC, Morais Neto OL, Moura L et al. (2008) Vigilância de fatores de risco para doenças crônicas por inquérito 
telefônico nas capitais dos 26 estados brasileiros e no Distrito Federal (2006). Rev Bras Epidemiol 11, Suppl. 1, 20-37.

18. Ministério da Saúde (2007) VIGITEL Brasil 2006. Vigilância de fatores de risco e proteção para doenças crónicas por inquérito telefónico: estimativas sobre freqüência e distribuição sócio-demográfica de fatores de risco e proteção para doenças crónicas nas capitais dos 26 estados brasileiros e no Distrito Federal em 2006. Brasília: Ministério da Saúde.

19. National Center for Chronic Disease Prevention and Health Promotion (2010) Behavioral Risk Factor Surveillance System. Atlanta, GA: CDC; available at http://www.cdc. gov/brfss/

20. Martinez ME, Marshall JR \& Sochrost L (1998) Invited commentary: factor analysis and the search for objectivity. Am J Epidemiol 148, 17-19.

21. Aromaa A, Koskinen S \& Huttunen J (1999) Health in Finland. Helsinki: National Public Health Institute and Ministry of Social Affairs and Health.

22. Helakorpi S, Uutela A, Prättälä R et al. (1999) Health Behaviour and Health Among the Finnish Adult Population, Spring 1999. Helsinki: National Public Health Institute.

23. Blaxter M (1990) Health and Lifestyles. London: Tavistock/ Routledge.

24. Patterson RE, Haines PS \& Popkin BM (1994) Health lifestyle patterns of US adults. Prev Med 23, 453-460.

25. Karisto A, Prättälä R \& Berg MA (1993) The good, the bad and the ugly. Differences and changes in health related lifestyles. In Regulating Markets - Regulating People. On Food and Nutrition Policy, pp. 185-204 [U Kjaernes, L Holm, M Ekström et al., editors]. Oslo: Novus.

26. Laaksonen M, Prättälä R \& Karisto A (2001) Patterns of unhealthy behaviour in Finland. Eur J Public Health 11, 294-300.

27. Rose G (1992) The Strategy of Preventive Medicine. Oxford: Oxford University Press.

28. Osler M, Heitmann BL, Gerdes LU et al. (2001) Dietary patterns and mortality in Danish men and women: a prospective observational study. Br J Nutr 85, 219-225.

29. Hu FB, Rimm E, Stampfer MJ et al. (2000) Prospective study of major dietary patterns and risk of coronary heart disease in men. Am J Clin Nutr 72, 912-921.

30. Fung TT, Willett WC, Stampfer MJ et al. (2001) Dietary patterns and the risk of coronary heart disease in women. Arch Intern Med 161, 1857-1862.

31. Williams DEM, Prevost AT, Whichelow MJ et al. (2000) A cross-sectional study of dietary patterns with glucose intolerance and other features of the metabolic syndrome. Br J Nutr 83, 257-266.

32. Slattery ML, Boucher KM, Caan BJ et al. (1998) Eating patterns and risk of colon cancer. Am J Epidemiol 148, 4-15.

33. Fung T, Hu FB, Fuchs C et al. (2003) Major dietary patterns and the risk of colorectal cancer in women. Arch Intern Med 163, 309-314.

34. Newby PK \& Tucker KL (2004) Empirically derived eating patterns using factor or cluster analysis: a review. Nutr Rev 62, 177-203. 